\title{
Cuestión de matices: el idioma de los argentinos, su ciencia y sus ancestros (sobre Borges y V.F. López) ${ }^{1}$
}

\author{
JUAN ANTONIO ENNIS Universidad Nacional de La Plata - CONICET, Argentina / juanennis@conicet.gov.ar
}

\begin{abstract}
Resumen
En estas páginas se ofrece un examen inicial de las tentativas filológicas de Vicente Fidel López acerca de las raíces indoeuropeas del idioma —y la cultura- de los incas, rastreando las fuentes bibliográficas de sus postulados y el contexto material de su aparición. Al mismo tiempo, se propone una hipótesis de lectura que tiende un puente entre sus postulados y los planteados más de medio siglo después por Jorge Luis Borges en su conferencia sobre el idioma de los argentinos, que más allá de su carácter puramente tentativo, permite observar el funcionamiento persistente de algunas operaciones básicas en la postulación de vínculos constitutivos entre las lenguas, la historia y los pueblos.
\end{abstract}

Palabras clave: V.F. López / J.L. Borges /

idioma de los argentinos / ciencias del lenguaje

\section{Nuances matter: The Argentinians' language, its science and its ancestors (on Borges and V.F. López)}

Abstract

The following pages intends to offer a preliminary approach to Vicente Fidel López's philological attempts on the alleged Indo-European roots of the Incas' language and culture, tracing back some of its most relevant scholarly sources, as well as depicting its material context of emergence. At the same time, a reading hypothesis is proposed, linking López's postulates with those sketched by Jorge Luis Borges on the issue of Argentine's own language more than half a century later. Its tentative nature notwithstanding, this approach should contribute to make visible the persisting work of some basic operations proper to the construction of constitutive bonds between languages, history and peoples.

Key words: V.F. López / J.L. Borges / Argentine's language / Language sciences

Recibido: 17/6/2019. Aceptado: 12/8/2019

Para citar este artículo: Ennis, J.A. (2019). Cuestión de matices: el idioma de los argentinos, su ciencia y sus ancestros (sobre Borges y V.F. López). El taco en la brea, 10 (junio-noviembre), 130-142. Santa Fe, Argentina: UNL. DOI: 10.14409/tb.v1i10.8693 
El 23 de septiembre de 1927 Jorge Luis Borges presenta en el Instituto Popular de Conferencias una conocida conferencia sobre la pregunta por el idioma de los argentinos, que entonces recorría las páginas de la prensa de muy diversas, siempre polémicas formas. La escena no debe ser desatendida, puesto que la conferencia, tal como reseña La Prensa al publicar el texto al día siguiente, ${ }^{2}$ cuenta con presencias notables, que le otorgan el rango de un acontecimiento. ${ }^{3}$ Borges, que venía además de tomar parte en la conocida polémica sobre el «meridiano intelectual» entre Madrid y Buenos Aires, sentaba aquí una posición ya esbozada en sus textos (muchos de ellos publicados también en la segunda sección dominical de La Prensa), y también en su participación en la encuesta realizada por el diario Crítica pocos meses antes a partir de la pregunta «iLlegaremos a tener un idioma propio?», desdeñando tanto el «arrabalero de los sainetes» como el afán casticista en el cuidado de un idioma que entiende aún mejorable, y que nunca deja de ser «nuestro idioma». ${ }^{4}$ La pregunta por un idioma de los argentinos interroga de hecho la posibilidad de pensar los límites de una comunidad nacional sobre la base de una lengua común cuyo carácter amenazado o inminente venía siendo objeto de discursos y debates diversos desde hacía entonces al menos medio siglo. Como es sabido, esta controversia se dirimía entre casticismos locales y ultramarinos y versiones más o menos estilizadas de las distintas variantes del español hablado en la ciudad de Buenos Aires, y en ningún caso ingresaba en la pregunta componente americano autóctono alguno. La lengua es una, es nuestra, y está para hacer una literatura. Finalmente anunciaba: «Vivimos una hora de promisión. Mil novecientos veintisiete: gran víspera argentina» (Borges:159). ¿Quiénes vivían esa hora de promisión? Ese «nosotros» acababa de ser claramente delimitado poco antes, al aseverar que en cuanto a la propiedad de un idioma, «mejor lo hicieron nuestros mayores». Es el nosotros de quienes pueden reclamar ese linaje, que no pasa solamente por los nombres, sino por el dominio de un modo de expresión, la capacidad de una autenticidad en el manejo de un lenguaje propio que - como acertadamente lo establece Bendix (52-53) para el caso de los Grimm — trabaja en el vínculo entre lengua y nación desde el Romanticismo sobre un paradójico juego de inclusión y exclusión. El balance del estándar a la manera de Bello (el uso de las clases cultas), equidistante de la imposición transatlántica y las variedades consideradas vulgares, adquiere su forma ejemplar en el pasado, en esta serie de ancestros comunes al nosotros que vive su hora de promisión:

El tono de su escritura fue el de su voz; su boca no fue la contradicción de su mano. Fueron argentinos con dignidad: su decirse criollos no fue una arrogancia orillera ni un malhumor. Escribieron el dialecto usual de sus días: ni recaer en españoles ni degenerar en malevos fue su apetencia.

A la hora de definir en qué consiste ese idioma de los argentinos a la imagen y semejanza de sus mayores, Borges niega de plano una posible ininteligibilidad mutua con el resto del español. «Un matiz de diferenciación sí lo hay: matiz que es lo bastante discreto para no entorpecer la circulación total del idioma y lo bastante nítido para que en él oigamos la patria». La patria de Borges parece aquí algo más distinto de aquella a la que Girondo atribuía poco antes la imparcialidad de un cuarto de hotel, pero la fe, también, está en la fonética, o más bien en la entonación. En fin, no es el léxico privativo lo que refiere Borges aquí, es el «ambiente distinto de nuestra voz, (...) la valoración irónica o cariñosa que damos a determinadas palabras, (...) su temperatura no igual». Borges arriesga alguna precisión más, pero en líneas generales podemos decir que su modo de 
intervenir en la discusión del idioma de los argentinos se resuelve no tanto en la preocupación por el primer término, sino en la clara delimitación del segundo. «Nosotros, los argentinos», entonces, para Borges, es algo que denomina a la descendencia de esos mayores que sí habrían dominado una lengua propia. ¿Quiénes son esos mayores?

Pienso en Esteban Echeverría, en Domingo Faustino Sarmiento, en Vicente Fidel López, en Lucio V. Mansilla, en Eduardo Wilde. Dijeron bien en argentino: cosa en desuso. No precisaron disfrazarse de otros ni dragonear de recién venidos, para escribir. (Borges:155)

Esta enumeración puede tener diversos motivos, entre los cuales puede incluirse sin dudas cierta arbitrariedad de la memoria o del azar de las lecturas, aunque sabemos que ambas cosas tienden a ser bastante limitadas en Borges. No obstante, más allá de los rasgos propios de la prosa de cada uno, esos nombres representan también algunas instancias salientes en la historia de la voluntad letrada criolla de dar con una forma propia del lenguaje, que nuevamente, en líneas generales no tendía a preocuparse gran cosa por las formas y sí, por el contrario, por el régimen de su propiedad. Así, corresponde a la generación de Echeverría el haber formulado el reclamo por la soberanía idiomática, y a Sarmiento el desarrollo de una más precisa instrumentación de la misma en Chile. En cuanto a Mansilla, si bien no se encuentran intervenciones notorias de su parte en estos debates, es ciertamente probable que la definición de Borges esté más cerca de encontrar su objeto en el tono de las Causeries que en el propio del resto del corpus representado en esos nombres. Y en las Causeries, por otra parte, también podemos encontrar indicios claros de cierto americanismo en materia de gestión de la lengua literaria. Eduardo Wilde tiene una intervención en la encendida polémica que en 1900 desata el libro de Lucien Abeille, Idioma nacional de los argentinos, sobre todo en torno a cuestiones que en principio parecen haberle sido ajenas. Wilde, al igual que muchos, se desentiende de Abeille para hablar con Ernesto Quesada de otros problemas, que conciernen sobre todo a la posibilidad de imponer la propia expresión cotidiana como norma viable en un conjunto mayor. ${ }^{5}$

En todos estos casos, el problema de la lengua de los argentinos no es el de la legitimación de una variedad portadora de una tradición hasta entonces vulgar que debe devenir popular para participar del relato de una posible soberanía que, como podía aparecer en Sarmiento, se extendiera de la política a la lengua, o de otro modo afirmara en la lengua lo que se pretendía en política. Borges lo deja más en claro que sus antecesores al afirmar que «ni hay un dialecto general de nuestras clases pobres: el arrabalero no lo es». En el caso más extremo, no se tratará más que de unos pocos rasgos a los que se otorga un alto valor icónico e indicial, muestras de pertenencia, shibboleths criollos. Si uno de ellos era, en la propuesta de reforma ortográfica de Sarmiento, por ejemplo, el seseo americano, ${ }^{6}$ en Borges se reduce a ese matiz, ese «ambiente» 0 «temperatura» de la voz argentina.

Leyendo justamente, entre otras cosas, las reflexiones del primer Borges sobre la traducción, así como la lectura y traducción que de Borges hace Mário de Andrade, Raúl Antelo señala cómo los martinfierristas, entre los que se contaba Borges, «se aplicaron, en diversos estilos, a una ontología nacional». Así, insiste, «querían atrapar la antropogénesis de lo criollo, rescatar el aporte intelectual de América Latina, previo tijeretazo al cordón umbilical». Esta que aparece como estrategia estética, encuentra en la «metafísica nacional» un complemento muy apropiado, «porque les tendía un puente más allá de lo animal, en dirección a la historia humana, occidental». La 
antropogénesis de lo criollo implica así una voluntad de pertenencia (a Occidente) y de diferencia (sin salir de él) con respecto a sus otros, y sobre todo, podría agregarse, con respecto a aquellos que — como había anticipado un largo coro encabezado por Hegel— no iban a ingresar ya en la historia. Como describe más ampliamente Antelo, se trata de una reapropiación que no deja de guardar «la memoria del desgarramiento originario». De este modo, se presenta esa identidad criolla como «la constante construcción de una diferencia, que es también la búsqueda, en sí misma, de un modo sudamericano de ser universal» (Antelo:122).

Esa búsqueda misma de un modo americano de ser universal, ese escape de la animalidad hacia un occidente apropiable, encuentra en la preocupación por una lengua propia pero no ajena a la tradición metropolitana una de sus líneas más fuertes y persistentes, y en la tradición que Borges construye en la evocación de «nuestros mayores», parece operarse una forma de esa búsqueda tan constante como errática: hay un «nosotros» que se distingue de una tradición occidental en la cual quiere recuperar para sí un lugar que aún no existe. Llamativamente, entre los nombres de la lista, hay uno que presenta un antecedente tan nítido como peculiar de esa búsqueda: Vicente Fidel López. Es en el corpus de su obra que se encuentra un antecedente notable para este anclaje de la diferencia del idioma de los argentinos en su entonación. No disponemos aún de documentación que demuestre una filiación directa; no sabemos si Borges había leído el texto, pero el parecido no deja de resultar notable. Sabemos, sí, que en la época y medios en los que circulaba Borges o su prosa, esta empresa no había sido olvidada. Al menos Arturo Costa Álvarez — presente en el escenario en la conferencia mencionada al inicio, y entonces colaborador habitual en el mismo suplemento de La Prensa en el que solía publicar Borges - lo recuerda con sorna en una nota del 2 de octubre de 1928 en La Prensa, a propósito de La esfinge indiana de José Imbelloni. ${ }^{7}$ Aun si Borges conocía el texto de López, si conocía sus hipótesis, e incluso en el caso de que hubiera encontrado allí el antecedente para el anclaje del matiz propio, de la diferencia sutil pero irreductible del idioma de los argentinos, es comprensible que prefiriera dejarlo de lado, e incluso guardar un piadoso silencio sobre él. Notablemente, el antecedente indígena ni siquiera ingresa en la serie de los rechazos (españoles, orilleros, reciénvenidos). Cuando entran luego, en la ficción, es de forma mediada y claramente en los lindes de la barbarie y la animalidad. ${ }^{8}$

En un texto de 1869, López describe lo que denomina «lengua argentina» como poseedora de una «fisonomía especial, en el cuerpo mismo del habla española», que reside en un modo de articularse, en un «acento característico», el cual «es un rasgo nuestro y precioso, que debemos conservar con tenacidad en la lengua argentina para consagrar con él el tipo de nuestro estilo y acabar de fundar así en todas sus faces la estructura completa y propia de nuestra nacionalidad». La similitud, puede verse, reside en esta postulación a futuro de una fundación de la nacionalidad en una forma propia de la lengua que, sin salirse de la matriz hispánica, se sustrae a su régimen, a partir de una diferencia tan sutil como radical en la música, la entonación de la lengua. Lo que de ninguna manera va a aparecer en Borges es la explicación, que reside en toda la extensa investigación que precede a la formulación de esta hipótesis. Este acento, según López, esta entonación peculiar y propia le vendría a la «lengua argentina» - también, como la argentinidad, ya entonces, aún futura-, naturalmente, del quechua: «El castellano en Sud-América, como el inglés en NorteAmérica, tomó un cierto tinte de ternura primitiva en el acento característico del tono simpático de los yaravís» (López, 1869d:542-543). 
El texto citado se publica inicialmente en una larga serie de entregas en la Revista de Buenos Aires dirigida por Vicente Quesada y Miguel Navarro Viola, a partir de 1865 y hasta 1869, y finalmente aparece como libro en París, bajo el nombre de Les races aryennes du Pérou. Leur langue-leur réligion - leur histoire (París, Franck - Montevideo, chez l’auteur), en 1871. La historia de su confección y traducción al francés - con la colaboración de un joven Gaston Maspero empleado para tal fin, y que en ese curioso trance a punto estuvo de detentar la primera cátedra de gramática comparada en Montevideo (Cordier, 1920: 97) — es un asunto aparte, ${ }^{9} \mathrm{y}$ aquí quisiera concentrarme en algunos aspectos singulares del texto tal como va apareciendo en la publicación, y en el modo en que llega a esta hipótesis. Se trata de una de las más notables empresas de simultánea incorporación de un discurso científicamente autorizado sobre las lenguas y los pueblos en estas latitudes, y a la vez de reformulación del indigenismo americanista que proliferara en los discursos de comienzos del XIX, y donde figura una incorporación que se ha dado en llamar «arqueológica» (Kaempfer, 2006; Fernández Bravo, 1997) o "patrimonial» (Pas) del pasado indígena, sino un intento de capitalización política a través de su integración en la configuración económica de la lengua nacional. Este doble movimiento, en la sugerencia o hipótesis final acerca de la «lengua argentina», se revela nuevamente como un esfuerzo por integrar a la nación argentina como sujeto histórico en un decurso universal (occidental) de la historia a través de vías contrarias a la de la herencia española. Si Echeverría había pronunciado en la Ojeada retrospectiva la necesidad de aceptar, bajo condición de mejora, el solo legado de la lengua de España, López señalará que lo más propio en ella viene de la presencia espectral del mundo prehispánico en su tono. Borges, por su parte, sustrae quirúrgicamente esta modulación, aunque deja una pista en el nombre de quien la articuló.

La Revista de Buenos Aires, dirigida por Vicente Quesada y Miguel Navarro Viola, comienza a editarse en mayo de 1863, y estaba dedicada a la publicación de investigaciones y documentos de distinta índole relacionados con la historia y presente americanos en general y especialmente de la Argentina. Prometiendo fundarse en «el gran contingente de una cooperación ilustrada por parte de los primeros hombres de letras y publicistas Americanos», y estableciendo su familiaridad con otras publicaciones mensuales «enteramente ajenas a la política» como La Revista del Pacífico y La Revista de Lima, la publicación daba espacio a diversas investigaciones divididas en cuatro secciones (derecho, historia, letras y variedades) que llevaban con frecuencia la firma de aquellos hombres de letras y publicistas que, inmersos entre otras cosas a través de esas labores en el fragor de la cotidianeidad política, procuraban un espacio de relativísima autonomía en el cual difundir estudios que, en última instancia, no hacían más que desembocar finalmente en su uso político: el de la participación en un relato de lo nacional, el de la capitalización de un patrimonio cultural o lingüístico para el archivo necesario a la constitución de la nación de la que todo Estado debía proveerse.

Autoproclamadamente ajena al fragor de la contienda partidaria, pero contribuyendo a pensar las bases históricas documentables y argumentables de la comunidad política deseada, una publicación de este tipo podía albergar discursos tendientes a la especialización y especificidad científica, que sin embargo contribuyeran a dar forma a una representación eminentemente política de la comunidad (americana o nacional). De este modo, la Revista de Buenos Aires demuestra en su prospecto y en los trabajos que publica un persistente interés por la indagación, estudio y puesta en valor de las lenguas y culturas originarias de América. Ya en el n ${ }^{\circ}$ 5, de agosto de 1863 , hay una primera intervención relacionada con el valor de las lenguas indígenas para la construcción de una 
historia del espacio nacional. En la misma, Vicente Quesada responde a una incertidumbre planteada por el propio Juan María Gutiérrez, en un artículo que, en la sección de «Historia americana» encabezaba la edición bajo el título de "Apuntes sobre el origen de la lengua quichua en Santiago del Estero», procurando establecer, sobre la base de distintos documentos de cronistas, historiadores y viajeros así como de los datos ofrecidos por la toponimia, la preexistencia de la presencia de la cultura incaica en el territorio ahora argentino al momento de la llegada de los españoles.

En el n ${ }^{\circ} 28$, de agosto de 1865 , aparecería la primera entrega del trabajo de V.F. López, precedido de una elogiosa introducción de J.M. Gutiérrez. La publicación en sucesivas entregas se repartirá en distintas series, desde la de los «Estudios filológicos y etnológicos sobre los pueblos y los idiomas que habitaban en el Perú al tiempo de la conquista», luego en 1867 el más extendido «Estudio sobre la colonización del Perú por los Pelasgos en los tiempos prehistóricos, demostrada por el análisis comparativo de las lenguas y de los mitos», en 1868 el «Sistema astronómico de los antiguos peruanos», y en 1869, las «Iniciaciones filológicas». El primer trabajo era una breve muestra de su procedimiento filológico en la indagación de los orígenes del quechua a partir del ejemplo de viracocha, en el que procuraba poner de manifiesto la comunidad de origen (y por tanto de destino) de las formas verbales y culturales egipcias, sánscritas y quechuas. «Esta es la verdad de los hechos. La duda no es posible para el hombre que haya ocupado seriamente sus vigilias en el estudio de estos problemas» (López, 1865:482).

Lo novedoso en el caso de esta serie de estudios reside tanto en lo aventurado de sus hipótesis como en el intento de introducirlas a través de la autoridad del discurso de las ciencias del lenguaje, de cuya esforzada apropiación da cuenta en las páginas introductorias. Si bien hoy, y muy probablemente entonces, las hipótesis propuestas y su formulación podían parecer improbables, si no disparatadas a más de un lector, el modo en que establece los parentescos y conclusiones obtiene cierta lógica interna y persigue un argumento que, si bien difícilmente podía ser defendido con éxito en su momento, podemos conjeturar que se encontraba dentro del terreno de lo enunciable. De hecho, una forma inicial de esta hipótesis puede encontrarse ya en el libro fundamental (aunque no mencionado explícitamente aquí) de Friedrich Schlegel, Über die Sprache und Weisheit der Indier (Sobre la lengua y la sabiduría de los hindúes) (1808), donde, a partir de los materiales que le había proporcionado Alexander von Humboldt (Schlegel:46; v. Quijada Mauriño:253), el menor de los Schlegel situaba a las lenguas americanas sin dudarlo en «un escalón más bajo» a partir del carácter «mecánico» de su construcción gramatical frente al «orgánico» de las lenguas flexivas, aunque mencionando al final del mismo capítulo la hipótesis en cuestión:

En el diccionario peruano también he encontrado, si bien de manera escasa, algunas raíces indias, como veypul, grande, indio vipulo; Ucini, reír, indio Indro. Si tiene algún fundamento la leyenda de que los Incas tenían su lengua propia sólo conocida y lícita para ellos, ahora completamente desaparecida, entonces quizás aquellas raíces de esta se hayan perdido en la lengua común; ya que de todos modos desde los libros de historia chinos que de Guignes nos ha dado a conocer se echa clara luz sobre el hecho de que los fundadores del Imperio peruano y su ilustración [Bildung] habrían llegado allí desde el oriente de la China o de las islas índicas. (Schlegel:58-59) ${ }^{10}$

A través de una serie de métodos y líneas de trabajo - como por ejemplo la detección en los numerales y pronombres del índice más fiable del parentesco entre lenguas-que sin duda había 
aprendido tanto de Max Müller como de Burnouf," la hipótesis con la que V.F. López pretende desafiar el saber establecido en el campo del estudio de las lenguas postula al quechua como una «lengua aria aglutinante». A pesar de su extravagancia, la propuesta del escritor argentino, habida cuenta de todas las limitaciones en su formación y desarrollo — que él mismo declaraba—no dejaba de reposar en antecedentes prestigiosos. Tal como señalaba ya Cordier (91), esta teoría no era menos aventurada (el término que utiliza el autor es por cierto abracadabrante) que muchas otras hallables en la bibliografía americanista.

López llama en su socorro a Bunsen y advierte de los reparos que una de las autoridades más eminentes en la lingüística de la época, August Friedrich Pott, opone a la amplitud de las filiaciones propuestas por este, que él mismo pretendía extender del inicial camino de Egipto a Grecia, Roma y la India, al Cuzco. Esta aspiración inclusiva en una historia que así se revela universal otorga sentido a la demanda que contienen las entregas del estudio de López de establecer el estudio de las lenguas indígenas en Argentina:

Esplicado localmente, toda su importancia, como eje de la civilización y de la época quichúa o Kéchua, se pierde en el aislamiento de las montañas americanas; y una fábula más o menos entre los grandes mitos que sirven a la vida de las naciones por todo el globo, es poca materia a los ojos de la filosofía de la Historia. Mas si ese mito perteneciera a las tradiciones primitivas de la humanidad, si como palabra y como punto histórico estuviese incluido en la vida positiva de los pueblos y fuese prueba incontrovertible de la unidad de lenguas, de razas y de ideas que liga a todas las naciones antiguas, el aspecto del problema y de su resolución habría cambiado profundamente y sería una de las adquisiciones más importantes y luminosas de la ciencia histórica. (López, 1865:473)

López tomaba así un nombre plástico y prestigioso y ponía a trabajar en él esas dos convicciones fundamentales de la lingüística decimonónica junto a la hipótesis tipológico-evolutiva que encontramos entre algunos de sus más renombrados autores, según la cual toda lengua flexiva tuvo que haber sido antes aglutinante y polisintética: los incas son tan o más indoeuropeos que los españoles, y la prueba gramatical en contra de esto, la divergencia tipológica, no sería tal, dado que representan simplemente un estadio anterior. De este modo consideraba Max Müller a las lenguas llamadas "turánicas», categoría que le servía para reunir todo lo que en Europa y Asia no fuera indoeuropeo en una tercera categoría común. En un largo ensayo que bajo el título de «The Last Results of the Researches respecting the Non-Iranian and Non-Semitic Languages of Asia and Europe, or the Turanian Family of Languages. (Letter of Prof. Max Müller to Chevalier Bunsen)» ocupaba la segunda mitad del primer volumen de los Outlines of the Philosophy of Universal History, applied to Language and Religion (1854), de Bunsen, Müller había desarrollado los avances de lo que llamaba «filología turaniana». A grandes rasgos, la categoría servía a Müller en primera instancia para persistir en el determinismo histórico documentable en la lengua deslindándolo del biológico o racial. «Turaniano» o «turánico» era un adjetivo que reunía en un hipotético parentesco a todas las lenguas que cayeran fuera del árbol indoeuropeo o semítico en el continente euroasiático («The Arian and Semitic languages occupy but four peninsulas of the primeval continent - India, Arabia, Asia Minor, and Europe; all the rest belongs to the family of Tur», 484) y fuera distinto del chino, desde el euskera y las lenguas finoúngricas hasta las del sudeste asiático, llegando su extensión incluso hasta Norteamérica y dejando abiertas más posibilidades a nuevas exploraciones. 
Como sintetizaría eficazmente Maspero años más tarde, «el turánico es más un estadio que una forma definida de una lengua» (Maspero:134). Pero este estadio suponía también un estadio previo en la civilización: las lenguas turanianas son las lenguas «nómades», las semíticas y arias las "políticas» (una distinción similar retoma V.F. López en la Revista del Río de la Plata en 1871). En todo este «mundo primigenio», las trazas del parentesco originario entre las distintas familias turánicas son mucho más distantes y difusas, por ser más antiguas y menos documentadas, que en el caso de indoeuropeos y semitas. Es de hecho el avance conquistador de estos el que va fragmentando un mapa rizomático y de contornos indefinidos, que al mismo tiempo, conjetura Müller, contendría los estadios iniciales de esas mismas civilizaciones. Es probablemente en esta hipótesis de los remotos y oscuros orígenes comunes que López se apoya para buscar en la también, desde la antigüedad, difusa figura de los pelasgos (cuyos rasgos, ubicación y hechos extrae del Herodoto de Rawlinson, publicado por primera vez en 1858), el ancestro común a incas e hindúes. Este ancestro común, migrando en dirección a oriente desde su origen mediterráneo, habría alcanzado aun en la temprana etapa aglutinante de las lenguas turánicas los Andes, pero ya llevando consigo el potencial civilizatorio indoeuropeo, detectable en sus representaciones de las divinidades, el universo, la organización política y la economía.

De este modo, así como la transliteración de la variedad oral de una lengua mayor hace aún más bárbara por contraste su expresión ante la variante escrita metropolitana, ${ }^{12}$ López a la inversa «orientaliza» en la transcripción los nombres de la toponimia local para posarlos sobre un plano de consistencia con la literatura filológica indoeuropeísta de la época, rechazando al mismo tiempo el legado filológico español: así, por ejemplo, Famatina deviene Phatma-tina (529), y al mismo tiempo des-orientaliza, al menos en parte, esa representación al presentar la de los incas como una expansión civilizatoria si no equivalente al menos alternativa, truncada por la conquista que, como hemos visto, les cae encima (533). Esto le permite reintroducir el tópico del desierto civilizatorio previo a la llegada de los españoles, para negarlo y finalmente invertirlo, para por la vía de la identificación de la conquista con la barbarie que arrasa con todos los signos de una civilización («los telares, la agricultura, la metalurgia...»—542-), llegar a la diferencia criolla en la lengua, antes mencionada. Será, por ejemplo, en el estudio de los numerales, que López simultáneamente corrija los errores de las gramáticas misioneras y establezca los parentescos con el camítico reportado por Bunsen y la vasta geografía turánica de Müller (que se apoyaba, justamente, en el estudio de estos elementos, para los que brindaba un útil cuadro al final de su ensayo), para insistir finalmente con la pertenencia del quechua a la misma raíz que las civilizaciones egipcia, griega, latina e hindú, hallando en esas analogías una "prueba evidentísima de la afinidad originaria del Keshua con todas esas familias de tribus heroicas que se nos presentan con tanto prestigio político en ese gran terreno de la historia clásica de que hasta ahora hemos tenido desheredadas a las tribus mártires de la América del Sud» (1865:196). De este modo, la reivindicación de López del pasado americano presenta justamente el problema de una transferencia de una forma de lo que hoy llamamos capital simbólico (prestigio) desde la historia clásica consagrada en Occidente hacia las «tribus mártires» - término que a su vez no es inocente, porque las incorpora en otra economía del sacrificio, que permite considerarlas extintas y al mismo tiempo integrarlas al panteón, al recinto sagrado del culto secular de las naciones modernas en construcción en el mismo espacio, a manos de los criollos.

Finalmente, el último trabajo de esta serie -el primero que mencionamos-, la «Geografía histórica del territorio argentino», retoma la comparación del Incario con la India, recurrente en 
cuanto a las tecnologías, estrategias y desarrollo del conocimiento, pero esta vez desplazando esa comparación hacia el esquema clásico para afirmar la grandeza de la estructura del imperio centrado en el Cuzco, «esa Roma Americana, cuyo nombre significa también urbs et orbs; centro y corazón del mundo: civitas» (López, 1869d:517). El razonamiento de López conducía de los pelasgos a Roma, y de Roma (antes de Roma) al Cuzco, y a su vez del Cuzco a Cosquín. El Cuzco reproduce la división cuatripartita en Capitolio-foro-civitas-ager de la urbs como modo de la «asociación romana (digamos pelasga)» (519), y lo traslada a los demás "centros coloniales» como queda documentado en su toponimia, en «sus nombres como otros tantos restos oseosos de un gran fósil» (521). Trasladando esta maquinaria deductivo-argumentativa a la toponimia y topografía cordobesas, concluirá en que «la civilización y la lengua de los quichuas, se hallaban pues a las puertas de lo que hoy es Buenos Aires cuando cayó sobre ellos la conquista española» (524).

El modo sudamericano de ser universal por el que está bregando aquí López sería accesible a través de la filología comparada, en un movimiento que se hace más claro en la siguiente entrega: las lenguas indígenas del presente no tienen nada que revelar más allá de su condición de archivo filogenético de la humanidad lingüística y culturalmente evolucionada. Los descendientes biológicos de los incas no son sus legatarios espirituales. Al igual que los hindúes del presente debían esperar a que William Jones les revelara el verdadero sentido de sus tradiciones (Errington:58), al igual que los egipcios del presente nada podían decir de sus jeroglíficos, los quechuahablantes del presente solo cuentan con una lengua que encierra secretos que el especialista criollo debe descifrar:

solo tengo en derredor ruinas y silencio. (...) Ningún libro habla. La raza que quiero estudiar guarda delante de mí la mudez y la impasibilidad de las Esfinges: se ha olvidado hasta de sí misma: ha sido hundida en las profundidades geológicas de la historia crepuscular de los siglos; y sus vencedores la ataron a la cadena de la fatalidad que la lleva irremediablemente a una muerte gradual, olvidada de sus tradiciones y hasta de las fábulas con que pudiera habernos dado el secreto de su vida. (...) En medio de estos sepulcros vivos de la antigüedad americana que llamamos Collas, Quichuas, Aimarás, nada más queda para poder penetrar el secreto de su origen (que tanto nos interesa) sino un idioma difícil y remoto que muy pocos entienden en el Río de la Plata. (López, 1865:6)

De este modo, la hipótesis de V.F. López acerca de la pertenencia del quechua a la familia indoaria, y su final conjetura acerca de la decisiva huella que la misma imprime en la lengua argentina por venir operan una doble y útil distinción en la economía política de la lengua nacional: por un lado, arraiga en el suelo prehispánico el matiz propio de la pertenencia argentina a Occidente, a través de España, fundando en ese matiz la nitidez de un futuro contorno propio. Por el otro, descarta de plano en ese deslinde cualquier posibilidad de contar, para esa construcción, con los indígenas mismos: solo sus lenguas servirán para tentar esta arqueología. Si puede pensarse que así como el Romanticismo venía a ser el liberalismo en literatura (Hugo dixit, y desde Larra hasta los románticos rioplatenses encontró bastante escucha), la filología histórico-comparada era el liberalismo en el discurso autorizado sobre las lenguas, es porque su irrupción implica en primer lugar una democratización de lo representable, una expansión masiva del corpus observado y ambicionado, y en términos de la definición del objeto, una emulación bastante prolija de la transferencia de soberanía al pueblo. Asimismo, la empresa de la filología histórico comparada implica también la reunión de denodados esfuerzos en pos de la formación de un mercado unificado, expandido y en expansión, 
una superficie o lenguaje común (v., entre otros, Bauman y Briggs, cap. 5). Este liberalismo trabaja sobre la diferencia no negándola ni promoviendo abiertamente su exterminio o exclusión, sino incluyéndola, capitalizándola, haciéndola propia, lo que quiere decir nada más y nada menos que incluirla en el régimen de propiedad que le da su orden y condiciones de existencia. Normalmente, el aparato metafórico desplegado en torno a las formas del contacto con lo otro (popular, indígena, exótico) resulta bastante elocuente en cuanto a la naturaleza económica del discurso en que se integra y el lugar que le corresponde en esa economía (materia prima, extracción primaria de lo «natural» normalmente en el espacio rural, que debe ser manufacturado por el letrado metropolitano). Así, el origen pelásgico, turaniano e indoeuropeo a un tiempo, del quechua, hubiera permitido, en el afán de López, persistir en la emancipación política y cultural del legado español, reivindicando al mismo tiempo para sí —y no para los indígenas aún presentes, que no participan de esa, con Antelo, antropogénesis criolla - una herencia americana integrada a la historia universal. En ese tono, ese matiz — ¿aquel en el que Borges quería oír la patria? — López encuentra el hilo entre una antigüedad clásica americana y un presente que aún pugnaba por ser moderno.

La que V.F. López llama «ciencia nueva» se había desarrollado en su forma más prestigiosa y difundida justamente persiguiendo interrogantes sobre los fundamentos últimos de la construcción de la comunidad a partir de la reconstrucción de una continuidad histórica atestiguada por la pertenencia a un tronco o rama común del lenguaje. Como lo han establecido distintas aproximaciones a la historia de la disciplina, «la emergencia de la filología comparada como campo coincidió con el recrudecimiento del sentimiento nacionalista que se extendió por los territorios germanoparlantes desde Königsberg hasta Constanza luego de la derrota infligida por Napoleón al Sacro Imperio Romano en 1806» (Benes:3). La tradición intelectual que emerge allí, la de la filología decimonónica, alberga la imaginación de «lenguas nacionales que dan forma a comunidades y prácticas culturales, así como a los patrones culturales y las identidades de aquellos que las hablan» (4). La continuidad cultural, sin embargo, venía garantizada por la pertenencia a un tronco común. La familiaridad entre las lenguas, su pertenencia a un mismo plano evolutivo, estaba codificada en la forma de su construcción gramatical. Por eso, en principio, la distancia con las lenguas americanas resultaría insalvable. Pero al mismo tiempo, la incorporación de sus formas más prestigiosas al tronco ancestral del indoeuropeo, y la reivindicación de una herencia que no perturba la gramática —ni la genética— - pero permite operar la distinción, la familiaridad, lo común dentro de una tradición que no dejaba de ser occidental pero permitía distinguirse de nativos e inmigrantes, más allá de su escaso éxito como hipótesis filológica, pudo encontrar en el "criollismo urbano de vanguardia» (Sarlo:60) practicado por Borges, una continuidad literaria tan tácita como estimable, y al mismo tiempo, como toda tradición, sensiblemente selectiva.

\section{Notas}

1 Este trabajo retoma y expande en parte lo desarrollado en Ennis (2018). Una instancia previa de lo expuesto aquí fue presentada en agosto de 2018 en el simposio de investigación «La lengua de los argentinos y las lenguas indígenas. Debates glotopolíticos en la constitución del Estado argentino», coordinado

por Jimena Néspolo. Agradezco especialmente a Graciela Goldchluk, directora de este dossier, la lectura crítica y los comentarios enriquecedores.

2 «El Instituto Popular de Conferencias realizó ayer su XIX sesión ordinaria. El señor Jorge Luis Borges hizo conocer un in- 
teresante trabajo sobre el idioma de los argentinos, que fue leído por el señor Manuel Rojas Silveyra - El doctor Arturo Capdevila hizo la presentación del conferenciante», La Prensa, 24 de septiembre de 1927.

3 Degiovanni y Toscano y García han sabido reponer en detalle los pormenores de esta intervención en un artículo imprescindible (2010).

4 Sobre la disputa del meridiano, pueden consultarse los trabajos de Bosoer; DiTullio (2009) o Falcón (2010a, 2010b); acerca de la encuesta del diario Crítica pueden leerse los trabajos de Sztrum; Oliveto, o el más reciente de Toscano y García.

5 Acerca de la polémica desatada por el libro de Abeille puede verse, entre otros, Rubione $(1983,2006)$, Di Tullio (2003, 2006), Ennis (2008, 2017), Alfón.

6 Ver al respecto Guitarte; Ennis (2008:124).

7 A propósito del debate entre Imbelloni y Costa Álvarez, véase el trabajo de Luisa Domínguez.

8 A este propósito puede leerse el interesante trabajo de Orrego Arismendi.

9 Tratado en el trabajo anteriormente mencionado (Ennis, 2018). A propósito de ello puede verse también Quijada
Mauriño; Palti (123-130); Jones; De Souza Rodrigues.

10 En todos los casos en que no se cita traducción publicada, la traducción es responsabilidad del autor del artículo.

11 Esto puede verse ya en la misma decisión de hablar de lenguas «arias», donde la incidencia de Burnouf y sobre todo de Müller se hace clara. Koerner da cuenta de la preferencia de Müller en este sentido del siguiente modo: "However, there was yet another term which had fairly wide currency in the 19th century, namely, "Aryan". In fact, from the early 1860s onwards, the Oxford professor of Sanskrit, Friedrich Max Müller (1823-1900), used "Aryan" in lieu of "IndoEuropean", and it appears to be owing to his very popular writings on language, philosophy, and many other subjects that this term became widely used in the Anglo-Saxon world. Müller justified his preference (similar to the manner in which other scholars had justified their particular term) by saying that, if "Aryan" is not a better term to denote the language family in question, it is at least the shorter one (Müller 1872, p. 11)» (Koerner:153-154).

12 El ejemplo característico es en este caso el de las lenguas criollas (v. Ennis y Pfänder, 2010, 2013).

\section{Referencias bibliográficas}

Alfón, F. (2013). La querella de la lengua en Argentina: ensayo biográfico. La Plata, Argentina: EdULP.

Antelo, R. (2008). Crítica acéfala. Buenos Aires, Argentina: Grumo.

Bauman, R. y Briggs, Ch. (2003). Voices of Modernity. Language Ideologies and the Politics of Inequality. Cambridge, Nueva York, Reino Unido y EE. UU.: Cambridge University Press.

Bendix, R. (1997). In Search of Authenticity. The Formation of Folklore Studies. Madison, EE. UU.: The University of Wisconsin Press.

Benes, T. (2008). In Babel's Shadow. Language, Philology and the Nation in Nineteenth-Century Germany. Detroit, EE. UU.: Wayne State University Press.

Borges, J.L. (1996 [1928]). El idioma de los argentinos. Buenos Aires, Argentina: Alianza.

Bosoer, S. (2008). Algo más que hispanismo-antihispanismo en la polémica por el meridiano: Lengua, nación y mercado a fines de la década de 1920. En Macciuci, R. (Dir.). Actas del I Congreso Internacional de Literatura y Cultura Españolas Contemporáneas. La Plata, Argentina: Facultad de Humanidades y Ciencias de la Educación, Universidad Nacional de La Plata.

Cordier, H. (1920). Maspero en Amérique. Journal de la Société des Américanistes, (12), 91-113.

Degiovanni, F. y Toscano y García, G. (2010). «Las alarmas del Doctor Américo Castro»: institucionalización filológica y autoridad disciplinaria. Variaciones Borges, (30), 3-42.

De Souza Rodrigues, J.P. (2013). Orientalismos americanistas: Vicente Fidel López, Francisco Adolfo de Varnhagen y los indígenas. Revista Complutense de Historia de América, (39), 59-80. 
Di Tullio, Á. (2003). Políticas lingüísticas e inmigración. El caso argentino. Buenos Aires, Argentina: Eudeba. (2006). Organizar la lengua, normalizar la escritura. En Rubione, A. (Dir.). La crisis de las formas. En Jitrik, N. (Dir.). Historia crítica de la literatura argentina, vol. 5. Buenos Aires, Argentina: Emecé, 543-580. (2009). Meridianos, polémicas e instituciones: el lugar del idioma. En Manzoni, C. (Dir.). Rupturas. En Jitrik, N. (Dir.). Historia crítica de la literatura argentina, vol. 7. Buenos Aires, Argentina: Emecé, 569-596.

Domínguez, L. (2019). El problema de las lenguas «prehistóricas». Un debate sobre el estudio de las lenguas indígenas a comienzos del siglo XX. Olivar, 19(29), e049. https://doi.org/10.24215/18524478eo49

Echeverría, E. (1991). Obras escogidas. Caracas, Venezuela: Bibliolteca Ayacucho.

Ennis, J. (2008). Decir la lengua. Debates ideológico-lingüísticos en Argentina desde 1837. Frankfurt, Alemania, et al.: Peter Lang.

(2017). La lengua al filo del siglo: las polémicas por el futuro del español de América en torno al 1900. Anuario de glotopolítica, (1), 197-228.

(2018). Las novedosas ciencias del lenguaje y la política de sus usos: Vicente Fidel López en la Revista de Buenos Aires (1863-1869). Boletín de la Sociedad Española de Historiografía Lingüística, (12), 53-74.

Ennis, J. y Pfänder, S. (2010). Zur fragwürdigen Legitimation des Laboratoriums Kreol(istik). En Ludwig, R. y Röseberg, D. (Eds.). Tout-Monde: Tout-Monde: Interkulturalität, Hybridisierung, Kreolisierung. Kommunikations- und gesellschaftstheoretische Modelle zwischen «alten» und «neuen» Räumen. Frankfurt, Alemania, et al.: Peter Lang, 257-282.

(2013). Lo criollo en cuestión. Filología e historia. Buenos Aires: Katatay.

Errington, J. (2008). Linguistics in a Colonial World. A Story of Language, Meaning and Power. Londres y Nueva York, Reino Unido y EE.UU.: Blackwell.

Falcón, A. (2010a). «Un español sin patria ninguna»: El idioma de los libros en tiempos de auge editorial. En Macciuci., R. (Dir.). Actas del IX Congreso Argentino de Hispanistas. La Plata, Argentina: Facultad de Humanidades y Ciencias de la Educación, Universidad Nacional de La Plata.

(2010b). El idioma de los libros: Antecedentes y proyecciones de la polémica «Madrid, meridiano "editorial" de Hispanoamérica». Iberoamericana, X(37), 39-58.

Fernández Bravo, Á. (1997). La frontera portátil: nación y temporalidad en Lastarria y Sarmiento. Revista Iberoamericana. LXIII(178/179), 141-147.

Guitarte, G.L. (1983). Seseo y distinción S-Z en América durante el siglo XIX. Siete estudios sobre el español de América. México, México: Universidad Nacional Autónoma de México, 107-125.

Jones, Ch. A. (2013). Liberalism, nationalism and Transnationalism in the Works and Life of Vicente Fidel López (1815-1903). Revista Complutense de Historia de América, (39), 39-57.

Kaempfer, Á. (2006). Lastarria, Bello y Sarmiento en 1844: Genocidio, historiografía y proyecto nacional. Revista de Crítica Literaria Latinoamericana, 63/64, 9-24.

Koerner, E.F.K. (1989). Observations on the sources, transmission, and meaning of «Indo-European» and related terms in the development of linguistics. Practising Linguistic Historiography. Selected Essays. Amsterdam y Philadelphia: John Benjamins, 149-177.

López, V.F. (1865). Estudios filológicos y etnológicos sobre los pueblos y los idiomas que habitaban en el Perú al tiempo de la conquista. La Revista de Buenos Aires. Historia Americana, literatura y derecho, III(29), 5-13; III(30), 183-196; III(31), 267-289; III(32), 437-459; III(33), 23-36.

- (1867). Estudio sobre la colonización del Perú por los Pelasgos en los tiempos prehistóricos, demostrada por el análisis comparativo de las lenguas y de los mitos. La Revista de Buenos Aires. 
Historia Americana, literatura y derecho, V(50), 143-169; V(51), 305-319; V(52), 442-463; V(53), 73-81.; V(54), 155-174; V(55), 293-308; V(56), 451-463. (1868). Sistema astronómico de los antiguos peruanos. La Revista de Buenos Aires VI(63), 270301; VI(64), 408-434.

- (1869a). Iniciaciones filolójicas. La Revista de Buenos Aires VII(72), 412-422.

(1869b). Iniciaciones filolójicas (carta segunda). La Revista de Buenos Aires VII(73), 51-65. (1869c). Dinastías peruanas según Montesinos. La Revista de Buenos Aires VII(79), 279-290. (1869d). Geografía histórica del territorio argentino. La Revista de Buenos Aires VII(79), 515-544. (1871a). Les Races aryennes du Pérou. Leur langue - leur religion - leur histoire. París: Franck. (1871b). Lengüística y política orgánica. Revista del Rio de la Plata. Periódico mensual de historia y literatura de América, I, 444-461.

Maspero, G. (1876). Histoire ancienne des peuples de l'orient. París, Francia: Hachette.

Müller, M. (1854). The Last Results of the Researches respecting the Non-Iranian and Non-Semitic Languages of Asia and Europe, or th Turanian Family of Languages. (Letter of Prof. Max Müller to Chevalier Bunsen). En Bunsen, Ch. Outlines of the Philosophy of Universal History, applied to Language and Religion. Londres, Reino Unido: Longman, 263-520.

Oliveto, M. (2010). La cuestión del idioma en los años veinte y el problema del lunfardo: a propósito de una encuesta del diario Crítica. Revista Pilquen, XII(13), 1-9.

Orrego Arismendi, J.C. (2007). Borges: sus cuentos sobre indios araucanos y el siglo xix. Variaciones Borges, $24,35-53$.

Palti, E. (2009). El momento romántico. Historia, nación y lenguajes políticos en la Argentina del siglo XIX. Buenos Aires, Argentina: Eudeba.

Pas, H. (2012). ¿Ecos de Lautaro? Las lenguas indígenas como patrimonio cultural del nacionalismo criollo en el siglo XIX. Anclajes, XVI(2), 73-92.

Quesada, V. (1863). Apuntes sobre el origen de la lengua quichua en Santiago del Estero. Revista de Buenos Aires, (5), 5-23.

Quesada, V.y Navarro Viola, M. (1863). Prospecto. Revista de Buenos Aires, (1).

Quijada Mauriño, M. (1996). Los «incas arios»: historia, lengua y raza en la construcción nacional hispanoamericana del siglo XIX. Historica, XX(2), 243-269.

Rawlinson, G. (1858-1860). The History of Herodotus. Londres, Reino Unido: Murray.

Rubione, A. (1983). En torno al criollismo. Buenos Aires, Argentina: CEAL.

(2006). Retorno a las tradiciones. En Rubione, A. (Ed.). La crisis de las formas, t. 5 de Historia Crítica de la Literatura Argentina. En Jitrik, N. (Ed.). Buenos Aires, Argentina: Emecé, 75-100.

Sarlo, B. (1982). Vanguardia y criollismo: la aventura de Martín Fierro. Revista de Crítica Literaria Latinoamericana, 8(15), 39-69.

Schlegel, F. (1808). Über die Sprache und Weisheit der Indier. Ein Beitrag zur Gründung der Alterthumskunde. Heidelberg, Alemania: Mohr und Zimmer.

Sztrum, M. (1998). ¿Llegaremos a tener un idioma propio? Encuesta en el diario Crítica, Buenos Aires, 1927. América. Cahiers du CRICCAL, 21, 219-225.

Toscano y García, G. (2019). El futuro de la lengua, la lengua del futuro. Sobre la encuesta del diario Crítica (1927). Olivar 19(29), e 052. https://doi.org/10.24215/18524478eo52

Wilde, E. (1983). El idioma y la gramática. En Rubione, A. (1983). En torno al criollismo. Buenos Aires, Argentina: CEAL, 67-101. 